\title{
Origin Matters: Diversity Affects the Performance of Alien Invasive Species but Not of Native Species
}

\author{
Yan Sun, ${ }^{1,2, *}$ Heinz Müller-Schärer, ${ }^{1}$ John L. Maron, ${ }^{3}$ and Urs Schaffner ${ }^{2}$ \\ 1. Department of Biology, University of Fribourg, Chemin du Musée 10, 1700 Fribourg, Switzerland; 2. CABI, Rue des Grillons 1, 2800 \\ Delémont, Switzerland; 3. Division of Biological Sciences, University of Montana, Missoula, Montana 59812
}

Online enhancement: appendix. Dryad data: http://dx.doi.org/10.5061/dryad.81nk5.

\begin{abstract}
At local scales, it has often been found that invasibility decreases with increasing resident plant diversity. However, whether resident community diversity similarly resists invasion by alien versus native species is seldom studied. We examined this issue by invading constructed native plant assemblages that varied in species and functional richness with invasive alien or native Asteraceae species. Assemblages were also invaded with spotted knapweed, Centaurea stoebe, a native European aster that has been previously used in diversity-invasibility experiments in North America. We also conducted a field survey to explore the generality of the patterns generated from our experimental study. Both experimental and observational work revealed that increasing diversity reduced the performance of alien but not native invaders. Centaurea stoebe invading its native community performed poorly regardless of resident diversity, whereas in a parallel, previously published study conducted in North America, C. stoebe easily invaded low-diversity but not highdiversity assemblages. Our results suggest that diversity is an attribute of resident communities that makes them more or less susceptible to invasion by novel invasive alien but not native plant species.
\end{abstract}

Keywords: community diversity, biogeographic, invasibility, invasive alien plants, native resident species, experimental and observational.

\section{Introduction}

Invasions by alien plant species threaten the integrity of agricultural and natural ecosystems and have become a major environmental issue (Gurevitch et al. 2011; Vilà et al. 2011). In addition to concern regarding their environmental impacts, research on biological invasions has been motivated by the fact that species introductions represent unprecedented biogeographic experiments that can shed light on fundamental questions in ecology and evolution (Callaway and Maron 2006). In particular, research in inva-

\footnotetext{
* Corresponding author. Present address: Division of Organisms and Environment, Department of Environmental Science, Policy, and Management, Berkeley, California 94720; e-mail: yan_sun@berkeley.edu.
}

sion biology has focused on three broad questions: (1) How do invasive alien species differ from noninvasive alien or native species in their capacity to invade recipient communities (i.e., invasiveness)? (2) What attributes of recipient communities make them susceptible to invasion (i.e., invasibility)? and (3) What is the impact of invasive alien species on native communities and ecosystems? (Alpert et al. 2000; Richardson and Pyšek 2006).

The biotic resistance hypothesis (Elton 1958) states that biotic interactions between resident native species and invaders can suppress the establishment and/or abundance of alien species in recipient communities. For plants, much work has focused on the competitive effects of resident native diversity in resisting invasion (Levine and D'Antonio 1999; Stachowicz et al. 1999; Jiang and Morin 2004; Fridley et al. 2007; Maron and Marler 2008). Experimental studies have generally found a negative relationship between resident diversity and invasibility (cf. reviews by Levine and D'Antonio [1999], Hooper et al. [2005], and Fridley et al. [2007]). The mechanism driving this pattern is most often found to be resource use complementarity, where fewer free resources are available for an invading species in assemblages with high versus low numbers of resident species (Loreau 1998; Spehn et al. 2000; Maron and Marler 2007). Based on a meta-analysis of biotic resistance to plant invasions, Levine et al. (2004) proposed that high richness of resident plant species primarily constrains the performance of alien plant species once they have established, rather than completely preventing invasions.

A number of studies addressing the diversity-invasibility relationship have used native plant species or a mixture of native and alien species as surrogates for invaders (Knops et al. 1999; Symstad 2000; Hector et al. 2001; Troumbis et al. 2002; Fargione et al. 2003; Pfisterer et al. 2004). This approach assumes that native and invasive alien species behave similarly during the early invasion process, but this has seldom been tested. In fact, recent studies suggest that competitive interactions between resident species with a shared evolutionary history may well differ from those be- 
tween resident and invasive alien plant species (Callaway et al. 2011; Sun et al. 2013).

Whether high native plant diversity inhibits invasion or performance of invasive alien and native plant species to the same extent can be tested in two ways. First, assembled native communities that differ in diversity can be experimentally invaded with native and invasive alien species so that the relationship between resident diversity and invasibility for each of these groups of species can be explicitly compared. Second, experimental communities that differ in native diversity can be assembled in an invader's native and introduced range. Using this approach, one can compare whether the long-term evolutionary history of a given species influences how it responds to resident diversity. That is, such a biogeographic comparison can elucidate not only how diversity affects invasibility but also whether this relationship varies depending on whether the invaded community is evolutionarily naive or shares a coevolutionary history with the invader. To our knowledge, this second approach has never been explored.

Finally, although the effects of resident diversity on invasibility have been examined in both small-scale experimental studies and larger-scale observational ones, seldom are both approaches employed simultaneously. The apparent discrepancy between results of experimental and observational diversity-invasion studies, at least in grasslands, may be due to differences in the scales studied (Levine 2000) and the different mechanisms affecting plant species richness at different spatial scales (Crawley and Harral 2001; Davies et al. 2005). Integrating experimental and observational work at a similar scale will thus greatly strengthen our understanding of the role of the diversity ecosystem functioning relationship for community invasibility.

Here, we used both experimental and observational approaches to examine the relationship between native plant diversity and invasibility. More specifically, we assembled native plant communities that differed in species and functional richness and compared effects of resident diversity on the performance (survival and growth) of several invasive alien and native species in the Asteraceae family. We also examined how native species diversity influenced the performance of Centaurea stoebe L., which is a potent invader in North America but is native to Europe, where our experiment was conducted. In a similar diversityinvasibility experiment previously conducted in North America, Maron and Marler $(2007,2008)$ found that $C$. stoebe heavily invaded low-diversity assemblages but performed more poorly in high-diversity plots. Thus, our goal was to determine whether $C$. stoebe responded similarly to diversity in its native range. Finally, we examined correlative patterns in the relationship between resident species diversity and performance of invasive alien and native species in field surveys to determine whether results ob- tained from experimental plots were congruent with those found in natural settings.

\section{Material and Methods}

Experimental Design of the Garden Plots

In March and April 2010, we created 42 unique native perennial plant assemblages in a southwest-facing grassland next to the CABI Centre $\left(47^{\circ} 37^{\prime} 30.01^{\prime \prime} \mathrm{N}, 7^{\circ} 32^{\prime} 63.89^{\prime \prime} \mathrm{E}\right)$ in Delémont, Switzerland. To facilitate comparison of the data from our experiment with those reported by Maron and Marler (2007, 2008), we used the same methods for selecting native plant species and constructing experimental plant assemblages as those described in Maron and Marler (2008). Plant assemblages varied in both species (two to 16 species) and functional groups richness (one to six functional groups; table 1). Experimental assemblages were composed of plants that commonly co-occur in European grasslands. As the functional diversity of resident plant communities is likely to affect the amount of untapped resources remaining for invaders (Fargione and Tilman 2005), we selected native plant species that varied in the timing and depth of resource uptake. As in Maron and Marler (2008), the 16 species that we used belong to the following six functional groups: grasses, early flowering forbs that branch with short rhizomes or stolons or at the root crown, midseason forbs with spreading rhizomes, midseason forbs with woody root crowns, early flowering ephemeral forbs with a shallow taproot, and late-season forbs with deep taproots (see table 1 for species names). Species from a specific functional group were randomly assigned when the native community contained several species from that functional group. Where different diversity plots had identical species and functional richness (i.e., treatments 5 and 6; see table 2), the plots varied in the functional groups from which species were drawn. In analogy, when diversity treatments with identical combinations of species and functional richness (e.g., treatments 2 vs. 3 ; see table 2) varied in functional identity, the functional identity was chosen randomly. Each diversity treatment was replicated six times, with replicates as random draws of species from a particular functional group.

\section{Experimental Procedure}

Seeds of 16 European perennial plant species were either collected in the field (bulk samples of 10-20 mother plants per population adjacent to sites with Centaurea stoebe populations) or purchased from commercial suppliers (Band-T World Seeds, Paguignan, France; UFA-Samen, Winterthur, Switzerland; and Jelitto, Schwarmstedt, Germany). 
Table 1: Native species, functional type, and code used in experimental assemblages

\begin{tabular}{|c|c|c|}
\hline Species & Functional group & Species code \\
\hline Bromus erectus Hudson ${ }^{\mathrm{a}, \mathrm{b}, \mathrm{c}, \mathrm{d}}$ & Grasses & $\mathrm{G}_{1 \mathrm{a}}$ \\
\hline Festuca valesiaca Schleich., ${ }^{c, d}$ & Grasses & $\mathrm{G}_{1 \mathrm{~b}}$ \\
\hline Koeleria pyramidata (Lam.) Beauv. ${ }^{\mathrm{b}, \mathrm{c}, \mathrm{d}}$ & Grasses & $\mathrm{G}_{1 \mathrm{c}}$ \\
\hline Primula veris (L.) Huds. ${ }^{a}$ & Early season, rhizomatous & $\mathrm{F}_{1 \mathrm{a}}$ \\
\hline Sanguisorba minor Scop. ${ }^{\mathrm{a}, \mathrm{c}}$ & Early season, rhizomatous & $\mathrm{F}_{1 \mathrm{~b}}$ \\
\hline Veronica teucrium L.c.d & Early season, rhizomatous & $\mathrm{F}_{1 \mathrm{c}}$ \\
\hline Achillea millefolium L., & Midseason, spreading rhizomes & $\mathrm{F}_{2 \mathrm{a}}$ \\
\hline Dianthus carthusianorum L., ${ }^{\mathrm{a}, \mathrm{c}}$ & Midseason, spreading rhizomes & $\mathrm{F}_{2 \mathrm{~b}}$ \\
\hline Galium verum $\mathrm{L}^{\mathrm{b}, \mathrm{c}, \mathrm{d}}$ & Midseason, spreading rhizomes & $\mathrm{F}_{2 \mathrm{c}}$ \\
\hline Artemisia campestris $\mathrm{L}^{\mathrm{b}, \mathrm{c}, \mathrm{d}}$ & Midseason, woody root crowns & $\mathrm{F}_{3 \mathrm{a}}$ \\
\hline Leontodon hispidus L. ${ }^{\mathrm{c}, \mathrm{d}}$ & Midseason, woody root crowns & $\mathrm{F}_{3 \mathrm{~b}}$ \\
\hline Scabiosa columbaria L. $^{\mathrm{a}, \mathrm{c}}$ & Midseason, woody root crowns & $\mathrm{F}_{3 \mathrm{c}}$ \\
\hline Plantago media L. $^{\mathrm{b}, \mathrm{c}, \mathrm{d}}$ & Spring ephemerals, shallow taproot & $\mathrm{F}_{4 \mathrm{a}}$ \\
\hline Ranunculus bulbosus L. ${ }^{c, d}$ & Spring ephemerals, shallow taproot & $\mathrm{F}_{4 \mathrm{~b}}$ \\
\hline Cichorium intybus L.c,d & Late season, deep taproot & $\mathrm{F}_{5 \mathrm{a}}$ \\
\hline Echium vulgare L. ${ }^{\mathrm{b}, \mathrm{c}, \mathrm{d}}$ & Late season, deep taproot & $\mathrm{F}_{5 \mathrm{~b}}$ \\
\hline
\end{tabular}

Note: $\mathrm{F}=$ forbs; $\mathrm{G}=$ grass species.

a Seeds collected from the field where Centaurea stoebe occurred.

b Seeds obtained from B-and-T World Seeds, Paguignan, France.

c Seeds obtained from UFA-Samen, Winterthur, Switzerland.

d Seeds obtained from Jelitto, Schwarmstedt, Germany.

Starting in January 2010, we grew individual plants from seeds in "cone-tainers" $(2.5 \mathrm{~cm} \times 16.5 \mathrm{~cm}$; Stuewe, Corvallis, OR) that were filled with a mixture of commercial soil (Selmaterra, Eric Schweizer, Thun, Switzerland), sand, and vermiculite (Vermisol, granular form, VTT, Muttenz, Switzerland) in the ratio $4: 2: 1$ in a greenhouse at the CABI Centre in Delémont, Switzerland. In March and April 2010, we transplanted plants into $3 \times 3-\mathrm{m}$ plots in a grassland next to the CABI Centre. To remove vegetation before setting up the experiment, we treated the plots with herbicide (Roundup Star, Monsanto Europe, Stähler
Suisse, Zofingen, Switzerland) twice up to 2 weeks before transplanting. We established 42 mixed-species plots $(7$ diversity treatments $\times 6$ replicates $=42$ plots), with each plot divided into four spatially separate $1.3 \times 1.3$-m subplots (separated by $0.2-\mathrm{m}$ buffer strips; see fig. A1; figs. A1-A3 available online). Subplots within plots were planted with identical mixtures of native species at identical initial densities of 48 individuals per subplot. Planted individuals that died were replaced in the spring during 2010-2012. The ultimate density of most species in subplots, however, was considerably higher than the planted density because

Table 2: Combination of species richness and functional richness used in experimental assemblages

\begin{tabular}{llcc}
\hline Treatment & \multicolumn{1}{c}{ Community composition } & Species richness & Functional richness \\
\hline 1 & $\mathrm{G}_{1 \mathrm{x}} \mathrm{G}_{1 \mathrm{y}}$ & 2 & 1 \\
2 & $\mathrm{G}_{1 \mathrm{x}} \mathrm{G}_{1 \mathrm{y}} \mathrm{F}_{2 \mathrm{a}} \mathrm{F}_{2 \mathrm{~b}} \mathrm{~F}_{2 \mathrm{c}}$ & 5 & 2 \\
2 & $\mathrm{G}_{1 \mathrm{x}} \mathrm{G}_{1 \mathrm{y}} \mathrm{F}_{3 \mathrm{a}} \mathrm{F}_{3 \mathrm{~b}} \mathrm{~F}_{3 \mathrm{c}}$ & 5 & 2 \\
2 & $\mathrm{G}_{1 \mathrm{x}} \mathrm{G}_{1 \mathrm{y}} \mathrm{F}_{2 \mathrm{x}} \mathrm{F}_{3 \mathrm{x}} \mathrm{F}_{3 \mathrm{y}}$ & 5 & 3 \\
3 & $\mathrm{G}_{1 \mathrm{x}} \mathrm{G}_{1 \mathrm{y}} \mathrm{F}_{1 \mathrm{x}} \mathrm{F}_{1 \mathrm{y}} \mathrm{F}_{2 \mathrm{x}} \mathrm{F}_{2 \mathrm{y}}$ & 6 & 3 \\
3 & $\mathrm{G}_{1 \mathrm{x}} \mathrm{G}_{1 \mathrm{y}} \mathrm{F}_{2 \mathrm{x}} \mathrm{F}_{2 \mathrm{y}} \mathrm{F}_{3 \mathrm{x}} \mathrm{F}_{3 \mathrm{y}}$ & 6 & 3 \\
3 & $\mathrm{G}_{1 \mathrm{x}} \mathrm{G}_{1 \mathrm{y}} \mathrm{F}_{1 \mathrm{x}} \mathrm{F}_{1 \mathrm{y}} \mathrm{F}_{2 \mathrm{x}} \mathrm{F}_{3 \mathrm{x}}$ & 6 & 4 \\
3 & $\mathrm{G}_{1 \mathrm{x}} \mathrm{G}_{1 \mathrm{y}} \mathrm{F}_{1 \mathrm{x}} \mathrm{F}_{2 \mathrm{x}} \mathrm{F}_{2 \mathrm{y}} \mathrm{F}_{3 \mathrm{x}}$ & 6 & 4 \\
4 & $\mathrm{G}_{1 \mathrm{x}} \mathrm{G}_{1 \mathrm{y}} \mathrm{F}_{1 \mathrm{x}} \mathrm{F}_{1 \mathrm{y}} \mathrm{F}_{2 \mathrm{x}} \mathrm{F}_{2 \mathrm{y}} \mathrm{F}_{3 \mathrm{x}} \mathrm{F}_{3 \mathrm{y}}$ & 8 & 4 \\
5 & $\mathrm{G}_{1 \mathrm{x}} \mathrm{G}_{1 \mathrm{y}} \mathrm{F}_{1 \mathrm{a}} \mathrm{F}_{1 \mathrm{~b}} \mathrm{~F}_{1 \mathrm{c}} \mathrm{F}_{2 \mathrm{a}} \mathrm{F}_{2 \mathrm{~b}} \mathrm{~F}_{2 \mathrm{c}} \mathrm{F}_{3 \mathrm{x}} \mathrm{F}_{3 \mathrm{y}}$ & 10 & 4 \\
6 & $\mathrm{G}_{1 \mathrm{x}} \mathrm{G}_{1 \mathrm{y}} \mathrm{F}_{1 \mathrm{a}} \mathrm{F}_{1 \mathrm{~b}} \mathrm{~F}_{1 \mathrm{c}} \mathrm{F}_{2 \mathrm{a}} \mathrm{F}_{2 \mathrm{~b}} \mathrm{~F}_{2 \mathrm{c}} \mathrm{F}_{3 \mathrm{a}} \mathrm{F}_{3 \mathrm{~b}} \mathrm{~F}_{3 \mathrm{c}}$ & 11 & 4 \\
7 & $\mathrm{G}_{1 \mathrm{a}} \mathrm{G}_{1 \mathrm{~b}} \mathrm{G}_{1 \mathrm{c}} \mathrm{F}_{1 \mathrm{a}} \mathrm{F}_{1 \mathrm{~b}} \mathrm{~F}_{1 \mathrm{c}} \mathrm{F}_{2 \mathrm{a}} \mathrm{F}_{2 \mathrm{~b}} \mathrm{~F}_{2 \mathrm{c}} \mathrm{F}_{3 \mathrm{a}} \mathrm{F}_{3 \mathrm{~b}} \mathrm{~F}_{3 \mathrm{c}} \mathrm{F}_{4 \mathrm{a}, \mathrm{b}} \mathrm{F}_{5 \mathrm{a}, \mathrm{b}}$ & 16 & 6 \\
\hline
\end{tabular}

Note: Where specific species identity is not shown (i.e., where there is an $x$ or $y$ subscript denoting species identity), for each replicate of that treatment, the species was drawn at random from the pool of three species comprising that functional group. $\mathrm{F}=$ forbs; $\mathrm{G}=$ grass species. See table 1 for details. 
of natural recruitment after abundant seed set in 2010-2012. Assemblages were watered from April to August in 2010 to help transplanted seedlings to survive. We regularly weeded the plots to maintain the assigned levels of species and functional richness. Moreover, continuous weeding during the whole experiment enabled us to remove plants when they were small, thereby minimizing disturbance.

\section{Target Species}

To compare how invasibility differed between invasive alien and native species, we chose three Asteraceae species (Senecio inaequidens DC., Aster lanceolatus Willd., and Rudbeckia laciniata L.) that are classified as invasive alien species in Switzerland and/or neighboring countries (Muller 2004; Wittenberg et al. 2006; European Network on Invasive Alien Species 2012; Hungarian Ministry of Rural Development 2012) and three Asteraceae species (Senecio jacobaea L., Leucanthemum vulgare Lam., and Carduus nutans L.) that are native to the area where the experiment was conducted, that can become locally dominant in European grasslands, and that are invasive in North American grasslands (USDA Natural Resource Conservation Service 2012). In addition, we also included the native Aster, C. stoebe, because it was used in a similar diversityinvasibility experiment conducted in its introduced range, in Montana (Maron and Marler 2007, 2008). In Europe, C. stoebe exists as two cytotypes, diploids and tetraploids, but so far only tetraploids have been recorded from its introduced North American range (Mráz et al. 2011); therefore, we used tetraploid European C. stoebe in our experiment.

All of the C. stoebe and S. inaequidens seeds and part of the $S$. jacobaea seeds used in this study were collected in grasslands in Switzerland and Germany; additional seeds of S. jacobaea were obtained from the Botanical Garden at Porrentruy (Jura, Switzerland), and seeds of the other target species were purchased from a commercial supplier specialized in the provisioning of Swiss wildflower seeds of known habitat provenance (UFA-Samen). Because initial attempts to invade the plots by sowing seeds largely failed (see "Discussion"), we transplanted an equal number of seedlings of the target species into the experimental plant assemblages.

Seedlings of C. stoebe and all six invasive alien and native target species were grown in the greenhouse during the winter of 2011/2012 and transplanted in April 2012 at the 4-8-leaf stage (similar within each species) into the field. Twenty individuals of each target species were marked and placed in a grid of 20 rectangles (each measuring $20 \mathrm{~cm} \times 25 \mathrm{~cm}$ ) in the central $1 \mathrm{~m}^{2}$ of a subplot. The four subplots within each plot were randomly chosen (1) for addition of an alien invasive species, (2) for addition of a native species, (3) for addition of C. stoebe, and (4) as a control (fig. A1). Each invasive alien and native species was replicated twice within a diversity level, resulting in six subplots with invasive alien species and native species per diversity level, respectively. Centaurea stoebe was replicated six times per diversity level.

At the same time, 10 individuals of each target species were transplanted in monocultures into three $0.7 \times 1.3-\mathrm{m}$ subplots that had been cleared of vegetation. To reduce effects from the accumulated aboveground biomass of native background vegetation, all mixture assemblages were cut $5 \mathrm{~cm}$ above ground level in autumn 2011.

\section{Data Collection from Garden Plot Experiment}

We estimated the percentage cover of all native plants and bare ground in September 2010 within a $1-\mathrm{m}^{2}$ quadrat placed in the center of all subplots within each plot to ensure that effects of native species diversity on invasibility were not due to different cover that might vary with diversity. Aboveground biomass within a central $1-\mathrm{m}^{2}$ quadrat of each subplot was harvested in autumn 2012, 8 months after transplanting the target species. We cut plants at ground level, sorted, and bagged by species. In addition, we counted the number of transplanted target plant seedlings that survived in each subplot, harvested these, and bagged them separately. Target plants that were grown in monocultures were also counted and then harvested, dried to a constant weight at $80^{\circ} \mathrm{C}$ for $72 \mathrm{~h}$, and weighed.

\section{Field Survey}

To contrast with our experimental results, we also conducted a field survey to assess the correlative relationship between target alien invader or native biomass and resident native species richness. Plots assessed in field surveys were at the same spatial scale as experimental plots. In field surveys, we targeted areas that supported two invasive alien species (S. inaequidens and Solidago gigantea) and/or two dominant native species (S. jacobaea and $L$. vulgare). Sites with either invasive or native species were surveyed in 2011 and 2012. From June to July 2011, we visited one site of each invasive alien species and one site of each dominant native species in Switzerland (see table A1, available online). At each site, twenty $1 \times 1$-m quadrats were selected using a stratified random sampling design in which assemblages were sampled that supported different densities of the target species, ranging from high cover of the target species to very few target plants present. In July 2012, we visited two additional sites of each target species in France and Switzerland, and we sampled ten $0.4 \times 0.6-\mathrm{m}$ quadrats at each site using a stratified random sampling design. In both 2011 and 2012, we scored 
the species richness of the resident vegetation and harvested all aboveground biomass of both the target species and resident plants of each assemblage, which were bagged separately. Harvested plant material was dried to a constant weight at $80^{\circ} \mathrm{C}$ for $72 \mathrm{~h}$ and weighed. In addition, we collected the density data of the target species of each plot in all sites in 2012. In total, we surveyed two to three sites of each invasive alien and native dominant species in Switzerland and France (see table A1). Data are deposited in the Dryad Digital Repository: http://dx.doi.org/10.5061 /dryad.81nk5 (Sun et al. 2015b).

\section{Statistical Methods}

Experimental Plots. It was difficult to simultaneously analyze the effects of species and functional richness, because both factors were highly correlated across assemblages (Pearson $r=0.93$ ), despite the fact that we varied both of them. We therefore used either species or functional richness as a covariate in separate models. Here we focused on examining effects of species richness, because in all cases models using species richness accounted for slightly more variation than models using functional richness.

We took a hierarchical approach to data analysis. We used linear mixed-effects models, which were fit using the lmer function obtained from the $\mathrm{R}$ package lme4, which uses maximum likelihood to estimate the model pa- rameters (Bates et al. 2011). General linear mixed models were calculated to examine the effects of species type (i.e., invasive alien vs. native) and assemblage species richness on (1) the survival of transplanted invasive alien and native plant individuals, (2) the biomass of invasive alien and native species, and (3) the total biomass (target and background vegetation). Species type and assemblage species richness were included as a fixed factor, plot (block) and target species identity nested within species type were treated as random factors, and species richness was used as a continuous covariate. To assess the influence of two low-diversity subplots with particularly high invader biomass (fig. 1) on the significant effect of species richness on the biomass of target invasive plant species, we also ran the model without these two data points; because the effect of species richness on invader biomass remained significant $\left(\chi^{2}=40.96, P<.001\right)$, we only report the results of the model with the full data set in "Results."

When analyzing the two species types separately by using mixed-effects regression models to analyze the correlation between biomass of target species and species richness, species richness was also included as a fixed effect, and plot (block) and target species identity nested within species type were treated as random factors. There were no interactions between species identity and species richness of the artificial assemblages (biomass of target species: both $\chi^{2}<3.61, P>.16$; number of surviving plants of the
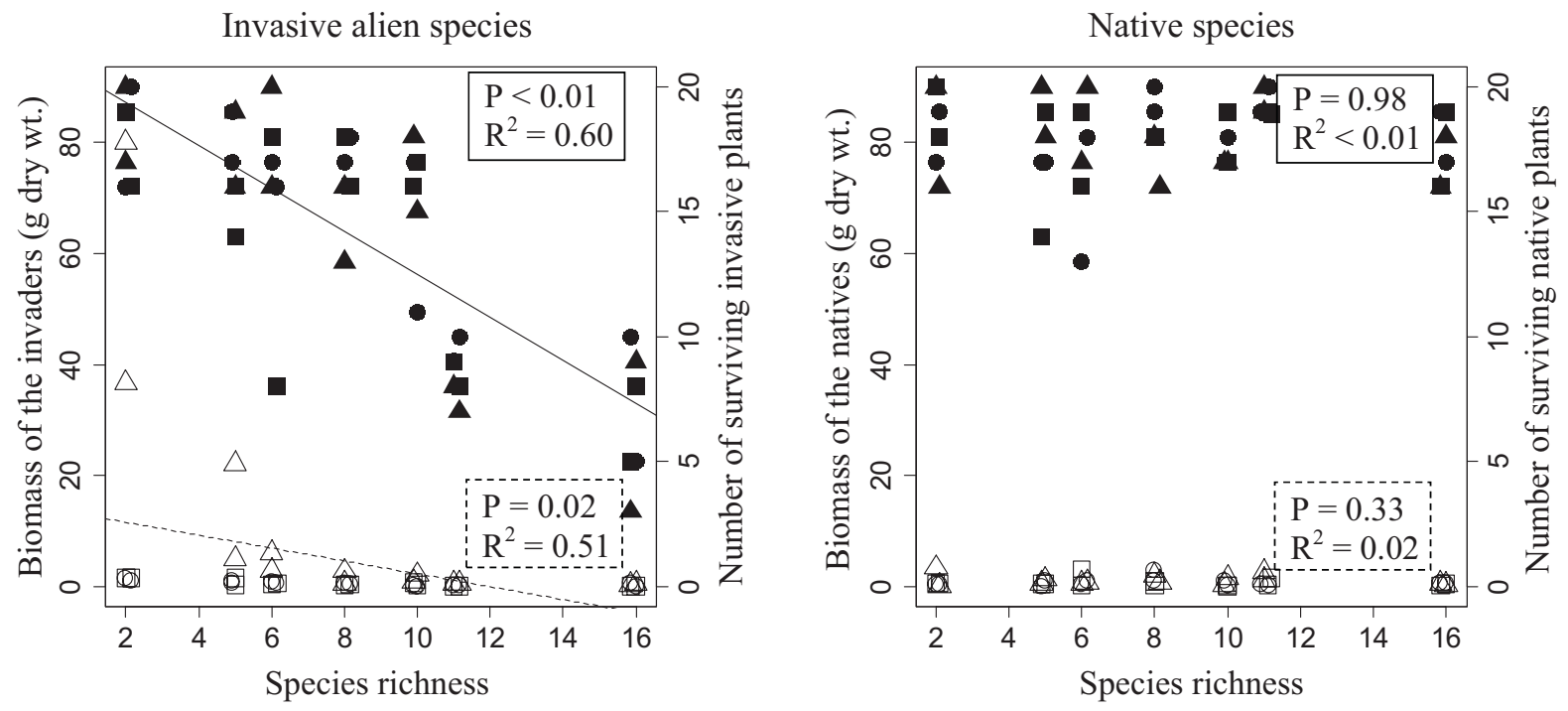

Figure 1: Results from experimental plots showing the relationship between resident native species richness and aboveground biomass (open circles and dashed line) and survival (filled circles and solid line) of target invasive alien species (left) and native species (right) transplanted into each plot. Each point represents the total biomass of transplanted individuals in a particular subplot. In the left panel, triangles represent Senecio inaequidens, squares represent Aster lanceolatus, and circles represent Rudbeckia laciniata, whereas in the right panel, triangles represent Senecio jacobaea, squares represent Carduus nutans, and circles represent Leucanthemum vulgare (each species is shown separately in fig. A2). For better visibility, biomass data points have been slightly shifted horizontally. 
target species: both $\chi^{2}<1.52, P>.47$; biomass of background vegetation: both $\left.\chi^{2}<0.78, P>.68\right)$. We thus combined species identity within species type to draw all figures, and we show the figure with each species separately in the appendix (fig. A2).

A general linear mixed model was used to test for differences between biomass of target species in recipient native community and in monoculture. In this model, species identity was treated as a random factor.

We used a one-way ANOVA to compare the biomass of C. stoebe in a recipient native community and in monoculture. We used paired $t$-tests to compare the biomass in uninvaded subplots with the biomass in subplots invaded by $C$. stoebe within the same plot.

Field Survey. Linear regression models were used to analyze the relationship between native species richness and biomass of target plants/total biomass of each site. Biomass data from each plot were standardized to dry weight (g) per square meter. All analyses were performed using R statistical software, version 2.15.1 (R Development Core Team 2012).

\section{Results}

Experimental Plots: Effect of Resident Diversity on Invasive Alien versus Native Species Invasibility and Centaurea stoebe Invasibility in the Home Range

Before the transplanting of the seedlings, resident cover in subplots was generally higher than $75 \%$ and did not differ among the diversity treatments $\left(F_{1,40}=0.17, P=.68\right)$. At harvest, the biomass of the background native community in the uninvaded subplots ranged from 459 to $1,875 \mathrm{~g}$ (fig. A3A) and increased with increasing diversity $\left(F_{1,40}=30.77, P<.001\right)$.

The biomass of transplanted target invasive alien species and native species in all native recipient subplots was significantly lower than in subplots in which the target species were grown in monocultures (on average, 97\% lower; both $\left.\chi^{2}>78.08, P<.001\right)$.

The analyses of biomass and survival of target species revealed a significant species type $\times$ species richness interaction (biomass of surviving target plants: $\chi^{2}=23.3, P<$ .001 ; number of surviving target plants, $\chi^{2}=22.9, P<$ $.001)$. Species richness had a strong negative effect on the biomass $\left(\chi^{2}=40.96, P<.001\right)$ and survival $\left(\chi^{2}=36.48\right.$, $P<.001$; fig. 1) of target invasive alien plants, whereas there were no significant effects of resident diversity on biomass $\left(\chi^{2}=0.30, P=.58\right)$ and survival $\left(\chi^{2}=0.0001, P=\right.$ .99; fig. 1) of target native plants. Biomass of the native community was, however, not correlated with the biomass and survival of target invasive alien and native species (bio- mass: both $\chi^{2}<1.16, P>.28$; survival: both $\chi^{2}<2.67, P>$ $.10)$.

The biomass of Centaurea stoebe in native community subplots was remarkably lower than that in monoculture (on average, 99\% lower; $F_{1,43}=131.2, P<.01$ ). However, neither resident species richness nor background native biomass affected the biomass (species richness: $F_{1,40}=$ $1.26, P=.27$; native biomass: $F_{1,40}=0.50, P=.48$ ) or survival (species richness: $Z=-0.96, P=.34$; native biomass: $Z=0.47, P=.64$ ) of $C$. stoebe (fig. $2 A, 2 B$ ). Total biomass of assemblages invaded by $C$. stoebe was similar to that of the paired uninvaded assemblages (paired $t$-test: $t=-1.02, \mathrm{df}=41, P=.31$; fig. A3A).

\section{Field Survey}

Across all field sites monitored over the 2 years, biomass of invasive alien target species decreased significantly with increasing resident diversity $\left(F_{1,8 \text { or } 18}>7.52, P<.03\right.$ and $F_{1,8 \text { or } 18}>5.13, P<.05$ for Solidago gigantea and Senecio inaequidens sites, respectively; fig. $3 A, 3 B$ ). Biomass of the native dominant target species, however, was not correlated with the background species richness $\left(F_{1,8 \text { or } 18}<\right.$ $0.67, P>.44$, and $F_{1,8 \text { or } 18}<2.45, P>.16$ for Leucanthemum vulgare and Senecio jacobaea sites, respectively; fig. $3 C, 3 D)$.

We found that the total plot biomass of invasive target species was significantly higher than that of native target species (on average, $522.78 \pm 29.03 \mathrm{~g} / \mathrm{m}^{2}$ vs. $223.92 \pm$ $\left.10.73 \mathrm{~g} / \mathrm{m}^{2}, \chi^{2}=5.88, P=.02\right)$. However, the density of invasive alien target species was not larger than that of the native target species (on average, 10.88 individuals $/ \mathrm{m}^{2}$ vs. 30.27 individuals $/ \mathrm{m}^{2}$ ) in the second-year survey.

\section{Discussion}

Our research generated several noteworthy results. First, we found strong negative relationships between resident native species richness in experimentally assembled communities and the performance of several invasive alien plants. Resident assemblages containing more species had greater negative impacts on alien growth and survival than did low-diversity assemblages. Second, although negative relationships between native diversity and invader performance were fundamentally strong for alien species, this was not the case if the invaders were natives. Native survival was high and growth was poor regardless of resident species diversity. Third, although a previously published parallel experiment revealed that the European species Centaurea stoebe strongly invades low-diversity (but not high-diversity) assemblages in North America, where it is a noxious weed (Maron and Marler 2007), C. stoebe performed poorly in our experiment in Europe regardless of 

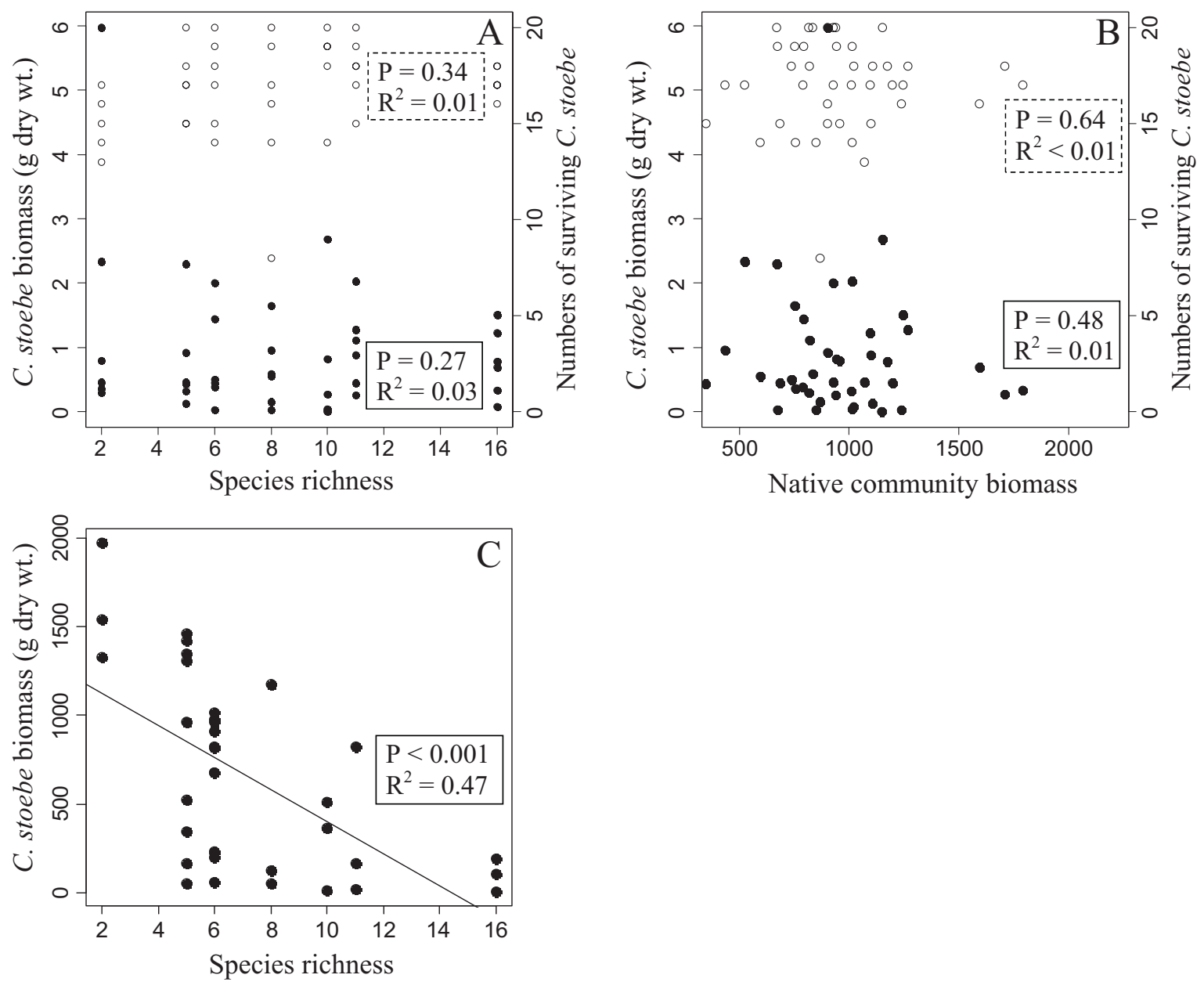

Figure 2: Results from experimental plots showing relationship between aboveground biomass (filled circle and solid line) and number of surviving plants (open circle and dashed line) for Centaurea stoebe transplanted into plots and the resident native species richness of those plots $(A)$ and the background resident native community biomass within plots $(B)$. For contrast, also shown are previous results from North America (reported in Maron and Marler 2008) describing the relationship between resident native species diversity and the biomass of C. stoebe that established from seed experimentally added to plots differing in native species richness (C). Each point represents a subplot. Note that, in Switzerland, experimental plots were invaded with seedlings of C. stoebe, whereas in North America plots were invaded with C. stoebe seed.

underlying resident diversity. Finally, the differences in the diversity-invasibility relationships between invasive alien and native species as revealed in our small-scale experiment were also found in correlative observational work in natural settings, and they were found again for several species of invaders.

\section{Invasive versus Native Target Species}

Classic ecological theory predicts that resource preemption should increase as the diversity and potential for niche overlap among resident species increases (MacArthur 1970; Case 1990). This prediction has been the basis for much of the work on diversity-ecosystem function relationships, because it suggests that there should be more complete resource uptake in high-diversity assemblages, which should lead to greater production of those assemblages compared with assemblages with fewer species (e.g., Hooper et al. 2005). However, the same logic applies to explaining why high-diversity assemblages might be more resistant to invasion than low-diversity ones. Within high-diversity assemblages, there should be fewer free resources available to an invading species than in low-diversity assemblages, which should make high-diversity assemblages more resistant to invasion. Our results, along with previous smallscale experimental work (Levine 2000; Naeem et al. 2000; Dukes 2001; Kennedy et al. 2002; Fargione et al. 2003; Zavaleta and Hulvey 2004), support this prediction. 

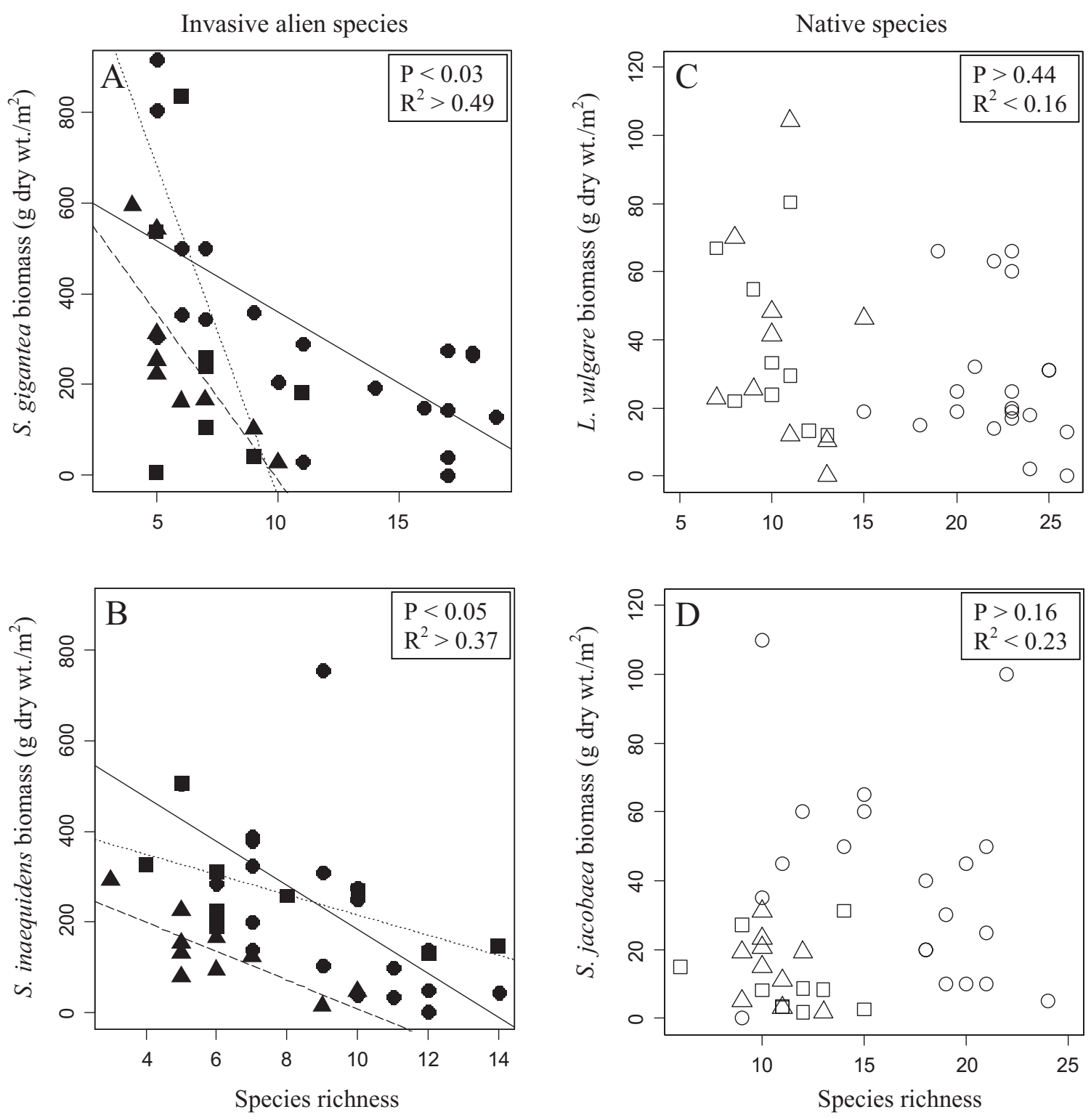

Figure 3: Results from field surveys showing the relationship between resident native species richness and target aboveground biomass of invasive species (filled bullet) Solidago gigantea $(A)$ and Senecio inaequidens $(B)$ and native dominant species (open bullet) Leucanthemum vulgare $(C)$ and Senecio jacobaea $(D)$. Circles (with solid regression line), triangles (long dashed regression line), and squares (dotted regression line) represent measures taken at the three different sites of each species.

Yet, while the survival and growth of alien invasives declined in species-rich assemblages, native invader performance did not change across the diversity gradient. In other words, native invaders were not able to increase their growth in the low-diversity plots, but they also managed to maintain high survival rates in the high-diversity plots. We do not know the mechanism(s) for these differences; however, we speculate that, in our field experiment, competition shifted from belowground to aboveground along the diversity gradient. In the uninvaded subplots, dry weight of the aboveground biomass increased from approximately $700 \mathrm{~g} / \mathrm{m}^{2}$ in the low-diversity plots to approximately $1,400 \mathrm{~g} / \mathrm{m}^{2}$ in the high-diversity plots. Natives may be better adapted than alien invaders to cope with high productivity and shading in high-diversity species assemblages, which explains their greater performance. At low diversity, invasive alien species may be able to better exploit untapped soil resources than natives. In comparison 
with the high productivity of grassland plant assemblages in Europe, the annual productivity in experimental studies assessing the diversity-invasibility relationship in North American grasslands is considerably lower (e.g., $\sim 250 \mathrm{~g} / \mathrm{m}^{2}$ in Fargione et al. 2003; 119-428 g/m $\mathrm{m}^{2}$ in Cleland et al. 2004; $200 \mathrm{~g} / \mathrm{m}^{2}$ in Maron and Marler 2008). The higher annual productivity in our field experiment, compared with those reported in North American field experiments, is likely to reflect a general trend of higher productivity in Europe than in the mixed-grass prairie in the intermountain western United States, where our target native species have become invasive and where the parallel experiment by Maron and Marler (2008) was conducted. In a field experiment conducted in southern Europe, seedlings of the invasive alien Senecio inaequidens experienced a mortality peak in summer during a period with combined temperature and water stress, suggesting that physiological trade-offs may reduce the ability of $S$. inaequidens to simultaneously tolerate shade and drought (Caño et al. 2007). In our low-diversity assemblages, competition for light must have been relatively high as well, but it might have allowed the invasive alien species to survive and access soil resources untapped by native species. Previous experimental studies have shown that invasion by alien species can lead to an increase in productivity of lowdiversity assemblages (Zavaleta and Hulvey 2004; Maron and Marler 2008). This may be particularly the case when an alien plant species possesses traits that are uncommon or even absent among resident native species that enable it to exploit soil resources that remain untapped in lowdiversity assemblages (see also the discussion of C. stoebe below).

An alternative explanation that has been put forward to explain why some alien plant species can become so dominant in the introduced range is that they possess allelopathic chemicals that are highly inhibitory to naive plants in the introduced range but that are relatively ineffective against their old neighbors (Hierro and Callaway 2003). However, it seems difficult to explain the negative diversity-invasibility relationship found in our study and in other experimental studies by allelopathy. If this mechanism is important, one would expect that invasive plants should do well regardless of resident diversity. A negative diversity-invasibility relationship might be found, however, if there is considerable variation among the resident plant species in coping with allelopathic substances that are released by plant invaders and potentially mediated by soil microbes (Vivanco et al. 2004) and if high-diversity assemblages are more likely than low-diversity assemblages to contain relatively resistant resident species. Evidence for significant variation in resistance to allelopathic substances released by plant invaders has been found in a previous study (Yang et al. 2007). However, if allelopathy was a gen- eral explanation, one might expect different patterns of invasibility to be found for invading species that are known to be allelopathic versus those that are not. As far as we know, this has not been the case in diversity-invasibility studies.

Herbivory on the target plant species in our experimental study was very low across all diversity treatments (Y. Sun, personal observation), suggesting that the difference in the performance and survival between native and alien invasive species cannot be due to top-down herbivore pressure. Moreover, even if herbivores preferentially consumed native over alien plant species, this would not create the observed difference between invasive and native species in the slope of the species richness-invasibility relationship.

\section{Centaurea stoebe}

Maron and Marler (2007) found that invasion by C. stoebe into experimental assemblages composed of North American native species decreased dramatically with increasing species richness of resident assemblages. Because of this strong diversity-invasibility relationship, C. stoebe had very high impact on the biomass of resident plants in lowdiversity assemblages but much reduced impact on less invaded high-diversity assemblages (Maron and Marler 2008). When we transplanted C. stoebe seedlings into plots, in contrast to the results reported in Maron and Marler (2008; fig. 2C), we found that C. stoebe performed poorly (in terms of survival and biomass) across all levels of diversity. Interestingly, when $C$. stoebe was added as seeds to bare subplots, it reached similar aboveground biomass as in the experiment conducted in Montana (Sun et al. 2015a). This further underlines that competition by the resident plants within experimental assemblages was generally high across all mixed-species assemblages (see above) and that $C$. stoebe was not able to exploit soil resources that remained untapped by old neighbors in the low-diversity assemblages.

The differences in the biodiversity effect of the resident community on old versus evolutionarily novel species may be explained by $C$. stoebe's greater exploitation of untapped resources in the low-diversity plots in the introduced range, whereas in the native range there may be more niche overlap with resident native species and thus greater competition for the same resources. A competition experiment by Sun et al. (2013) supports this idea. Sun et al. (2013) initiated a pairwise competition experiment in which C. stoebe competed against 15 European and 15 North American neighbor species. They found that the biomass of $C$. stoebe was correlated with the biomass of the native neighbors, as one might predict if species compete for similar resources. However, when C. stoebe competed against naive neighbors from the introduced range, 
biomass accumulation of $C$. stoebe was not related to the biomass of neighboring plants. Thus, competition with an evolutionarily novel species may be affected by exploitation of resources that are not used by the new neighbors. Sun et al. (2013) also provided experimental evidence that most old European neighbors are as efficient in exploiting soil moisture as $C$. stoebe, irrespective of whether they belong to the same or a different functional group. This fundamental difference in resource exploitation may explain the fact that total biomass of C. stoebe-invaded experimental assemblages was greater than the biomass of the paired uninvaded assemblages in the introduced range (fig. A3B) but not in the home range (fig. A3A).

Although the differences between our results and those of Maron and Marler (2007) are intriguing, it is important to note that the experiments in Montana and Switzerland were not exact replicas of each other. Most importantly, experimental plots in Montana were invaded with seeds of C. stoebe, whereas in Switzerland C. stoebe was introduced at the seedling stage. We initially also invaded subplots with seeds of C. stoebe, but no individuals established from seed in any of the diversity treatments. Germination was only observed in bare subplots and later produced similar aboveground biomass as in the experiment conducted in Montana, suggesting that differences in seed quality or geocytotypes between the two ranges cannot explain the lack of germination of $C$. stoebe in the diverse subplots in Switzerland (Sun et al. 2015a). This contrast in itself is revealing, in that it indicates that native assemblages are substantially more difficult for $C$. stoebe to invade than are assemblages in the introduced range. The Montana versus Switzerland comparison of results of invasibility is somewhat hindered because, in Montana, ultimate invader biomass was based on patterns of seed germination, seedling establishment, and subsequent performance of adult plants, whereas in Switzerland our results reflect seedling performance only. However, because seedling recruitment was not affected by the level of diversity of the background plant community in the Montana experiment (Maron and Marler 2007), it is reasonable to assume that most of the biotic resistance detected in that experiment occurred, as proposed by Levine et al. (2004), after the seedling establishment stage.

\section{Observational Studies}

Although our experimental study (and others) using constructed plant communities that varied in diversity showed negative effects of diversity on invader performance, many observational studies of the spatial correlation between diversity and invasion suggest that diverse native communities tend to be more invasible (see the review by Fridley et al. 2007). The majority of these observational studies have been performed at large spatial scales and have focused on the relationship between native and alien species richness, rather than native species richness and the abundance of a single alien invasive species, as done in our study. Comparisons between observational and experimental studies can be difficult due to differences in scale between these two approaches (Davies et al. 2005) and because observational studies include confounding external factors, such as resource heterogeneity or variable propagule supply, that can influence diversity-invasibility relationships. For example, Rejmánek (2003) showed that the positive native-exotic plant richness relationships reported by Stohlgren et al. (2003) in their analysis in the United States became negative when human population density and latitude were included in a regression analysis. However, observational studies assessing the relationship between native and alien species richness at fine scale also provided mixed results (Fridley et al. 2007).

Our observational study focused on the survival and growth of single alien invasive species and therefore differs from a large number of studies assessing the diversityinvasibility relationship by comparing the richness of native and alien species (Fridley et al. 2007). The number of established alien species and measures of the local dominance of alien invasive species are response variables of invasibility that address different aspects of the invasion process (Blackburn et al. 2011) and that are likely to be influenced by different processes. Although the establishment of alien species is considerably influenced by human activities and their effect on disturbance and propagule availability (e.g., Pyšek et al. 2010), the local dominance of established alien species, which ultimately affects their environmental impact (Parker et al. 1999), is predominately affected by their competitive abilities under the local biotic and abiotic conditions. Separating studies assessing the establishment phase from those assessing the build-up of local dominance of alien invasive plant species may at least partly explain the variation in the effect of native species richness on invasibility as revealed by observational studies. This is supported by Cleland et al. (2004), who found that native and nonnative species richness were positively correlated, but correlations between native richness and the relative abundance of alien plant species were predominately negative. Other observational studies assessing the relationship between native diversity and performance of established invasive alien species at fine scale also revealed a negative relationship (Prieur-Richard et al. 2000; Kolb et al. 2002). This provides support for the notion that high richness of resident plant species reduces invasibility by constraining not only the establishment but also, or even more consistently, the performance of alien plant species once they have established (Levine et al. 2004). 


\section{Conclusions}

Our results suggest fundamental differences in competitive interactions between invasive alien species and resident species in the home versus invaded community. The results from the experimental and the observational studies, which covered a similar range of resident species richness and which revealed that grass-dominated resident communities that resemble the low-diversity artificial assemblages of the experimental study indeed exist in nature, indicate that local species richness is a good predictor of the performance of invasive alien species but not of native species. The only other experimental study we are aware of that actively introduced both native and invasive alien plant species into experimentally created plant assemblages did not distinguish between the effect of species diversity on the performance of native plant species and invasive alien plant species (Fargione et al. 2003). However, our results cast doubt on using native species as surrogates of invasive alien species when studying mechanisms underlying habitat invasibility and other aspects of biological invasions. The biogeographic comparison also suggests that the effects of species diversity on invasibility by invasive alien plants depends on the overall habitat productivity, but a thorough test of this hypothesis would need a comparison among multiple sites differing in overall productivity.

We propose that experimental and observational studies need to be well coordinated to facilitate their interpretation and advance the theoretical understanding of exotic species' invasions. By selecting multiple plots with variable invader biomass within the same meadow, we attempted to minimize variation in external factors in the observational study. This may at least partly explain why the relationship found in our observational study is well in line with the findings from our experimental study.

\section{Acknowledgments}

Thanks to A. Brown, C. Closca, B. Eichenberger, D. Frey, N. Gendre-Miyazaki, N. Häfliger, A. Junod, S. Nacambo, P. Pardo Martínez, F. Schindelholz, H. Stéphane, C. Stickelberger, M. Stokvis, E. Tarboush, H.-Y. Xu, and L. Zaquini for assistance with fieldwork. We thank S. Lachmuth for supplying seeds of Senecio inaequidens; D. Frey for population information in Switzerland; and O. Argagnon, B. Poinso, and R. Sforza for population information about S. inaequidens and Senecio jacobaea in France. The study was funded through the National Centre of Competence in Research "Plant Survival" (to U.S. and H.M.-S.) and the Swiss National Science Foundation (grant 31003A _125314 to H.M.-S.). J.L.M.'s research was funded by the National Science Foundation (grants DEB-0318719 and DEB-0614406).

\section{Literature Cited}

Alpert, P., E. Bone, and C. Holzapfel. 2000. Invasiveness, invasibility and the role of environmental stress in the spread of non-native plants. Perspectives in Plant Ecology, Evolution and Systematics 3:52-66.

Bates, D., M. Maechler, and B. Bolker. 2011. lme4: linear mixedeffects models using S4 classes. R package version 0.999375-34. http://CRAN.R-project.org/package $=$ lme4.

Blackburn, T. M., P. Pyšek, S. Bacher, J. T. Carlton, R. P. Duncan, V. Jarošík, J. R. U. Wilson, et al. 2011. A proposed unified framework for biological invasions. Trends in Ecology and Evolution 26:333-339.

Callaway, R. M., and J. L. Maron. 2006. What have exotic plant invasions taught us over the past 20 years? Trends in Ecology and Evolution 21:369-374.

Callaway, R. M., L. Waller, A. Diaconu, R. Pal, A. Collins, H. MüllerSchärer, and J. L. Maron. 2011. Escape from competition: neighbors reduce Centaurea stoebe performance at home but not away. Ecology 92:2208-2213.

Caño, L., J. Escarré, and F. X. Sans. 2007. Factors affecting the invasion success of Senecio inaequidens and S. pterophorus in Mediterranean plant communities. Journal of Vegetation Science 18:281-288.

Case, T. J. 1990. Invasion resistance arises in strongly interacting species-rich model competitive systems. Proceedings of the $\mathrm{Na}$ tional Academy of Sciences of the USA 87:9610-9614.

Cleland, E. E., M. D. Smith, S. J. Andelman, C. Bowles, K. M. Carney, M. Claire Horner-Devine, J. M. Drake, et al. 2004. Invasion in space and time: non-native species richness and relative abundance respond to interannual variation in productivity and diversity. Ecology Letters 7:947-957.

Crawley, M. J., and J. E. Harral. 2001. Scale dependence in plant biodiversity. Science 291:864-868.

Davies, K. F., P. Chesson, S. Harrison, B. D. Inouye, B. A. Melbourne, and K. J. Rice. 2005. Spatial heterogeneity explains the scale dependence of the native-exotic diversity relationship. Ecology 86:1602-1610.

Dukes, J. S. 2001. Biodiversity and invasibility in grassland microcosms. Oecologia (Berlin) 126:563-568.

Elton, C. S. 1958. The ecology of invasions by animals and plants. Methuen, London.

European Network on Invasive Alien Species (NOBANIS). 2012. Gateway to information on invasive alien species in north and central Europe. http://www.nobanis.org.

Fargione, J., C. S. Brown, and D. Tilman. 2003. Community assembly and invasion: an experimental test of neutral versus niche processes. Proceedings of the National Academy of Sciences of the USA 100:8916-8920.

Fargione, J. E., and D. Tilman. 2005. Diversity decreases invasion via both sampling and complementarity effects. Ecology Letters 8: 604-611.

Fridley, J. D., J. J. Stachowicz, S. Naeem, D. F. Sax, E. W. Seabloom, M. D. Smith, T. J. Stohlgren, et al. 2007. The invasion paradox: reconciling pattern and process in species invasions. Ecology 88:3-17.

Gurevitch, J., G. A. Fox, G. M. Wardle, Inderjit, and D. Taub. 2011 Emergent insights from the synthesis of conceptual frameworks for biological invasions. Ecology Letters 14:407-418.

Hector, A., K. Dobson, A. Minns, E. Bazeley-White, and J. Hartley Lawton. 2001. Community diversity and invasion resistance: an experimental test in a grassland ecosystem and a review of comparable studies. Ecological Research 16:819-831. 
Hierro, J. L., and R. M. Callaway. 2003. Allelopathy and exotic plant invasion. Plant and Soil 256:29-39.

Hooper, D. U., F. S. Chapin III, J. J. Ewel, A. Hector, P. Inchausti, S. Lavorel, J. H. Lawton, et al. 2005. Effects of biodiversity on ecosystem functioning: a consensus of current knowledge. Ecological Monographs 75:3-35.

Hungarian Ministry of Rural Development. 2012. Invasive plants in Hungary. http://www.termeszetvedelem.hu/index.php?pg = menu _1731.

Jiang, L., and P. J. Morin. 2004. Productivity gradients cause positive diversity-invasibility relationships in microbial communities. Ecology Letters 7:1047-1057.

Kennedy, T. A., S. Naeem, K. M. Howe, J. M. H. Knops, D. Tilman, and P. Reich. 2002. Biodiversity as a barrier to ecological invasion. Nature 417:636-638.

Knops, J. M. H., D. Tilman, N. M. Haddad, S. Naeem, C. E. Mitchell, J. Haarstad, M. E. Ritchie, et al. 1999. Effects of plant species richness on invasion dynamics, disease outbreaks, insect abundances and diversity. Ecology Letters 2:286-293.

Kolb, A., P. Alpert, D. Enters, and C. Holzapfel. 2002. Patterns of invasion within a grassland community. Journal of Ecology 90:871881.

Levine, J. M. 2000. Species diversity and biological invasions: relating local process to community pattern. Science $288: 852-854$.

Levine, J. M., P. B. Adler, and S. G. Yelenik. 2004. A meta-analysis of biotic resistance to exotic plant invasions. Ecology Letters 7:975989.

Levine, J. M., and C. M. D’Antonio. 1999. Elton revisited: a review of evidence linking diversity and invasibility. Oikos 87:15-26.

Loreau, M. 1998. Separating sampling and other effects in biodiversity experiments. Oikos 82:600-602.

MacArthur, R. H. 1970. Species-packing and competitive equilibrium for many species. Theoretical Population Biology 1:1-11.

Maron, J. L., and M. Marler. 2007. Native plant diversity resists invasion at both low and high resource levels. Ecology 88:2651-2661.

2008. Effects of native species diversity and resource additions on invader impact. American Naturalist 172:S18-S33.

Mráz, P., R. S. Bourchier, U. A. Treier, U. Schaffner, and H. MüllerSchärer. 2011. Polyploidy in phenotypic space and invasion context: a morphometric study of Centaurea stoebe s.l. International Journal of Plant Sciences 172:386-402.

Muller, S. 2004. Plantes invasives en France: état des connaissances et propositions d'actions. Vol. 62. Collection patrimoines naturels. Muséum National d'Histoire Naturelle, Paris.

Naeem, S., J. M. H. Knops, D. Tilman, K. M. Howe, T. Kennedy, and S. Gale. 2000. Plant diversity increases resistance to invasion in the absence of covarying extrinsic factors. Oikos 91:97-108.

Parker, I. M., D. Simberloff, W. M. Lonsdale, K. Goodell, M. Wonham, P. M. Kareiva, M. H. Williamson, et al. 1999. Impact: toward a framework for understanding the ecological effects of invaders. Biological Invasions 1:3-19.

Pfisterer, A. B., J. Joshi, B. Schmid, and M. Fischer. 2004. Rapid decay of diversity-productivity relationships after invasion of experimental plant communities. Basic and Applied Ecology 5:5-14.

Prieur-Richard, A. H., S. Lavorel, K. Grigulis, and A. D. Santos. 2000. Plant community dynamics and invasion by exotics: invasion of Mediterranean old fields by Conyza bonariensis and Conyza canadensis. Ecology Letters 2:412-422.

Pyšek, P., V. Jarošík, P. E. Hulme, I. Kühn, J. Wild, M. Arianoutsou, S. Bacher, et al. 2010. Disentangling the role of environmental and human pressures on biological invasions across Europe. Proceedings of the National Academy of Sciences of the USA 107:1215712162.

R Development Core Team. 2012. R: a language and environment for statistical computing. R Foundation for Statistical Computing, Vienna.

Rejmánek, M. 2003. The rich get richer-responses. Frontiers in Ecology and the Environment 1:122-123.

Richardson, D. M., and P. Pyšek. 2006. Plant invasions: merging the concepts of species invasiveness and community invasibility. Progress in Physical Geography 30:409-431.

Spehn, E. M., J. Joshi, B. Schmid, M. Diemer, and C. Korner. 2000. Above-ground resource use increases with plant species richness in experimental grassland ecosystems. Functional Ecology 14:326337.

Stachowicz, J. J., R. B. Whitlatch, and R. W. Osman. 1999. Species diversity and invasion resistance in a marine ecosystem. Science 286:1577-1579.

Stohlgren, T. J., D. T. Barnett, and J. T. Kartesz. 2003. The rich get richer: patterns of plant invasions in the United States. Frontiers in Ecology and the Environment 1:11-14.

Sun, Y., A. R. Collins, U. Schaffner, and H. Müller-Schärer. 2013. Dissecting impact of plant invaders: do invaders behave differently in the new range? Ecology 94:2124-2130.

Sun, Y., H. Müller-Schärer, J. L. Maron, and U. Schaffner. 2015a. Bio-geographic effects on early establishment of an invasive alien plant. American Journal of Botany 104:1-5.

2015b. Data from: Origin matters: diversity affects the performance of alien invasive species but not of native species. American Naturalist, Dryad Digital Repository, http://dx.doi.org/10.5061 /dryad.81nk5.

Symstad, A. J. 2000. A test of the effects of functional group richness and composition on grassland invasibility. Ecology 81:99-109.

Troumbis, A. Y., A. Galanidis, and G. D. Kokkoris. 2002. Components of short-term invasibility in experimental Mediterranean grasslands. Oikos 98:239-250.

USDA Natural Resource Conservation Service. 2012. Plants database. http://plants.usda.gov/java/.

Vilà, M., J. L. Espinar, M. Hejda, P. E. Hulme, V. Jarošík, J. L. Maron, J. Pergl, et al. 2011. Ecological impacts of invasive alien plants: a meta-analysis of their effects on species, communities and ecosystems. Ecology Letters 14:702-708.

Vivanco, J. M., H. P. Bais, F. R. Stermitz, G. C. Thelen, and R. M. Callaway. 2004. Biogeographical variation in community response to root allelochemistry: novel weapons and exotic invasion. Ecology Letters 7:285-292.

Wittenberg, R., M. Kenis, T. Blick, A. Hänggi, A. Gassmann, and E. Weber. 2006. Invasive alien species in Switzerland: an inventory of alien species and their threat to biodiversity and economy in Switzerland. No. 0629. Environment in practice. Federal Office for the Environment, Bern, Switzerland.

Yang, R. Y., L. X. Mei, J. J. Tang, and X. Chen. 2007. Allelopathic effects of invasive Solidago canadensis L. on germination and growth of native Chinese plant species. Allelopathy Journal 19:241-247.

Zavaleta, E. S., and K. B. Hulvey. 2004. Realistic species losses disproportionately reduce grassland resistance to biological invaders. Science 306:1175-1177. 